\title{
Clinical epidemiology of prevalence and cardiovascular risk factors of nonalcoholic fatty liver disease among the elderly agricultural and fishing population in Taiwan
}

\author{
Chi-Te Sun ${ }^{1}$, Ming-Chih Chen ${ }^{1}$, Hsi-Che Shen ${ }^{2}$, Yi-Chun Hu ${ }^{3,4}$, Yu-Fen Chen ${ }^{5,6}$ and Tao-Hsin Tung ${ }^{7,8}$ \\ ${ }^{1}$ Graduate Institution of Business Administration, College of Management, Fu Jen Catholic University, Taiwan \\ ${ }^{2}$ Taipei Medical University, Taipei, Taiwan \\ ${ }^{3}$ College of Nursing, Taipei Medical University, Taipei, Taiwan \\ ${ }^{4}$ Oriental Institute of Technology, Taipei, Taiwan \\ 5Institute of Health and Welfare Policy, National Yang-Ming University, Taipei, Taiwan \\ ${ }^{6}$ Department of Nursing, Kang-Ning Junior College of Medical Care and anagement, Taipei, Taiwan \\ ${ }^{7}$ Department of Medical Research and Education, Cheng Hsin General Hospital, Taipei, Taiwan \\ ${ }^{8}$ Department of Crime Prevention and Correction, Central Police University, Taoyuan, Taiwan
}

\begin{abstract}
Purpose: To explore any gender-related differences in prevalence of and cardiovascular risk factors related to non-alcoholic fatty liver disease (NAFLD) amongst the elderly agricultural and fishing population in Taipei, Taiwan.

Methods: The study participants were conducted with a total of 6,511 (3,971 males and 2,540 females) healthy elderly subjects voluntarily admitted to a teaching hospital for a physical check-up in 2010. Blood samples and real-time ultrasound-proved fatty liver sonography results were collected.

Results: The prevalence of NAFLD for this elderly study population was found to be $27.2 \%$, the proportion revealing a statistically significant decrease with increasing population age $(\mathrm{p}<0.001)$. Females showed a greater prevalence of NAFLD than did males $\left(34.1 \%\right.$ vs. $22.7 \%$, $p$-value for $\chi^{2}$-test $\left.<0.001\right)$. Using multiple logistic regression analysis, in addition to female gender, a younger age, higher ALT, higher BMI, presence of hypercholesterolemia, hypertriglyceridemia, lower HDL, and higher fasting plasma glucose were the significant factors associated with NAFLD. Gender-related differences as regards associated factors were also revealed. For females, hypertension (OR=1.18, 95\%CI: 1.00-1.40), and lower HDL (OR=1.31, 95\%CI: 1.10-1.56) were significantly related to NAFLD but these were not so for males.
\end{abstract}

Conclusion: Several gender-related differences were noted pertaining to the prevalence of and relationship between hypertension, lower HDL, and NAFLD in this occupational elderly study population.

\section{Introduction}

Nonalcoholic fatty liver disease (NAFLD) is known as a common chronic liver disease that has been shown to progress to fibrosis, cirrhosis and liver failure [1,2]. The prevalence of NAFLD is reported to be in the $3-24 \%$ range in the general population in various countries, which is increasing in parallel with the increased prevalence of obesity $[1,3]$. In additional, non-alcoholic steatohepatitis (NASH) is a syndrome characterized by the association of fatty liver and lobular hepatitis and chronically elevated alanine aminotransferase plasma levels [4]. Eventually, NASH could be lead to nonalcoholic, noncholestatic cirrhosis and probably hepatocellular carcinoma [5]. From the clinical viewpoint, increased NASH could develop liver fibrosis as much as reaching $50 \%$ [4]. The early detection of this liver disorder by routine screening followed by appropriate clinical intervention would offer a practical means for the prevention of condition-associated hepatocellular damage.

NAFLD is matched the Wilson criteria for screening due to it is an important health problem; the disease natural history should be understood; a recognisable latent or early symptomatic stage; a test is easy to perform and interpret, acceptable, accurate, reliable, sensitive and specific; an accepted treatment recognised for the disease; treatment is more effective if started early; a policy on who should be treated; diagnosis and treatment are cost-effective; and case-finding should be a continuous process. Undoubtedly, the requirements of good health and appropriate training for agricultural and fishing population are necessary. The long hours or irregular working hours may cause some adverse health effects. To the best of our knowledge, however, few clinical evidence-based studies attempted to determine the prevalence and possible etiology of an GSD for the elderly agricultural and fishing

Correspondence to: Tao-Hsin Tung, Cheng Hsin General Hospital, Shih-Pai, 112, Taipei, Taiwan, Tel: 886-2-28264400-7704, Fax: 886-2-28264550, E-mail: ch2876@chgh.org.tw

Key words: agricultural and fishing population, elderly, gender difference, nonalcoholic fatty liver disease

Received: September 28, 2017; Accepted: October 25, 2017; Published: October 28,2017 
Sun CT (2017) Clinical epidemiology of prevalence and cardiovascular risk factors of nonalcoholic fatty liver disease among the elderly agricultural and fishing population in Taiwan

population of Taiwan, which also faced to the burden of health-related disease. In order to identify the prevalence of and associated risk factors for GSD, this study was designed to explore the potential for conditionrelated gender difference, because it was considered that such difference might underscore important implications for the understanding of the overall pathogenesis of GSD in this sub-elderly population. As above, the purpose of this study is to explore such gender difference in the context of prevalence of and cardiovascular risk factors for GSD amongst the elderly agricultural and fishing population, as determined by the application of a healthy volunteer subjects screening program health examination in Taipei, Taiwan.

\section{Methods}

\section{Study design and data collection}

In brief, this cross-sectional study was conducted with a total of 6,542 elder healthy occupational adults with agricultural and fishing professional fields (2,553 females and 3,989 males) voluntarily admitted to one teaching hospital in Northern Taiwan for an annual physical check-up between January 2010 and December 2010. Blood samples and ultrasound sonography results were collected. After excluding subjects without sonography information, the remaining $6,511(2,540$ females and 3,971 males) were enrolled to analyses.

Fasting blood samples were drawn via venipuncture from study participants by clinical nurses. Overnight-fasting serum and plasma samples (from whole blood preserved with EDTA and $\mathrm{NaF}$ ) were kept frozen $\left(-20^{\circ} \mathrm{C}\right)$ until ready for analysis. Definitions of the following diseases / conditions were high fasting plasma glucose (FPG) $\geq 110$ $\mathrm{mg} / \mathrm{dl}$, obesity: a body mass index $(\mathrm{BMI}) \geq 25 \mathrm{Kg} / \mathrm{m}^{2}$, hypertension: a high systolic blood pressure (SBP) $\geq 140 \mathrm{mmHg}$ or high diastolic blood pressure (DBP) $\geq 90 \mathrm{mmHg}$, hypercholesterolemia $(\geq 200 \mathrm{mg} / \mathrm{dL})$, and hypertriglyceridemia ( $\geq 200 \mathrm{mg} / \mathrm{dL}$ ). Serum ALT level $\geq 40 \mathrm{U} / \mathrm{L}$ were classified as elevated [6]. All procedures were performed in accordance with the guidelines of our institutional ethics committee and adhered to the tenets of the Declaration of Helsinki. All patients' information were anonymous.

\section{Ultrasound examination and diagnosis}

Hepatic ultrasonography was performed by the well-trained ultrasonographist using a Toshiba Nemio (SSA-550A) ultrasound probe. The ultrasonographic criteria which were used to diagnose fatty liver included liver and kidney echo discrepancy, presence of an increased liver echogenicity, echo penetration into the deep portion of the liver, and clarity of the liver blood vessel structures [47]. All study subjects who were diagnosed as NAFLD at out-patient department by ultrasound and without disease history of Wilson's disease, intestinal bypass surgery, or gulten enteropathy, ingestion of of drugs known to produce hepaticsteatosis including methotrexate, tamoxifen, amiodarone, and nucleoside analogues, positive serology for hepatitis B or C virus, a history of another known liver disease, and alcohol consumption (alcohol intake of $30 \mathrm{~g} /$ day or more for males and $20 \mathrm{~g} /$ day or more for females) were enrolled the study [8]. In addition, the degree of NAFLD on ultrasonography was classified as follows: Grade 1 (mild), steatosis: predominantly macrovesicular; involves up to $66 \%$ of lobules. Ballooning: occasionally observed, zone 3 hepatocytes. Lobular inflammation: scattered and mild acute inflammation (polymorphonuclear cells) and occasional chronic inflammation (mononuclear cells). Portal inflammation: none or mild; Grade 2 (moderate), steatosis: any degree, usually mixed macrovesicular and microvesicular. Ballooning: obvious and present in zone 3. Lobular inflammation: polymorphonuclear cells may be noted in association with ballooned hepatocytes, pericellular fibrosis, mild chronic inflammation may be seen. Portal inflammation: mild to moderate; Grade 3 (severe), steatosis: typically involves $>66 \%$ of lobules (panacinar), commonly mixed steatosis. Ballooning: predominantly zone 3, marked. Lobular inflammation: scattered acute and chronic inflammation, polymorphonuclear cells may be concentrated in zone 3 areas of ballooning and perisinusoidal fibrosis. Portal inflammation: mild to moderate $[9,10]$.

\section{Measurements of interobserver and intraobserver reliability}

In order to assure a consistent diagnosis of NAFLD between specialists, the Kappa statistic was used to assess the agreements of interobserver and intraobserver reliability among two study specialists. The pilot study was performed with randomly selected 50 randomly selected healthy subjects other than the study subjects. For interobserver reliability, the Kappa values for diagnosis of NAFLD was 0.77 (95\% CI: 0.69-0.88). The intraobserver reliability for the diagnosis of NAFLD for one specialist was 0.81 (95\% CI: 0.76-0.87). For the other specialist, the Kappa values was 0.83 (95\% CI: 0.73-0.91).

\section{Statistical analysis}

Statistical analysis was performed using SAS for Windows, (SAS version 9.1; SAS Institute Inc., Cary, NC, USA). For univariate analysis, the two-sample independent $\mathrm{t}$-test method was adopted to assess differences in the mean value of continuous variables between subjects with and without NAFLD. Multiple logistic regression was also performed to investigate the independence of factors associated with the prevalence of NAFLD. A p-value of $<0.05$ was considered to represent a statistically significant difference between two test populations.

\section{Results}

As Table 1 shows, the overall prevalence of NAFLD for the study participants was $27.2 \%(1,769 / 6,511)$. This parameter revealing a statistically significant decrease with increasing study-subject age by means of the $\chi^{2}$ trend test $(\mathrm{p}<0.001)$. The prevalence of NAFLD for female $(34.1 \%)$ proved to be substantially greater ( $\mathrm{p}$ value for $\chi^{2}$ test $<0.0001$ ) than it was for males (22.7\%). In addition, study-participating females exhibited a more-pronounced prevalence of NAFLD for all age groups than was the case for the male group after stratifying by age into one of four age groups. The age-specified prevalence of NAFLD revealed a significant positive relationship with age when applying the $\chi^{2}$ trend test $(\mathrm{p}<0.001)$ for both male and female study subjects.

Table 2 indicates the results of the comparison of a variety of test characteristics and their potential association with the NAFLD class value (yes or no) for study-included elderly agricultural and fishing screened subjects. Using the two-sample independent $t$-test, the associated factors that were significantly related to NAFLD included lower age, higher SBP, higher DBP, higher ALT, higher BMI, higher total cholesterol, higher triglyceride, lower HDL, and higher FPG. In addition to age, ALT, total cholesterol, triglyceride, HDL and fasting plasma glucose were the significant factors associated with NAFLD for both in males and in females. Table 3 shows gender-related differences as regards associated factors to NAFLD. SBP, DBP, and BMI were significantly related to NAFLD only for female subjects.

The effect of independent associated risk factors upon NAFLD was examined using the multiple logistic regression model. As is depicted in Table 4, subsequent to adjustment for confounding factors, gender 
Sun CT (2017) Clinical epidemiology of prevalence and cardiovascular risk factors of nonalcoholic fatty liver disease among the elderly agricultural and fishing population in Taiwan

Table 1. The gender and age specific prevalence of NAFLD among elderly agricultural and fishing screened subjects $(n=6,511)$.

\begin{tabular}{|c|c|c|c|c|}
\hline Variables & $\begin{array}{l}\text { Screened } \\
\text { No. }\end{array}$ & $\begin{array}{c}\text { NAFLD } \\
\text { No. }\end{array}$ & $\begin{array}{c}\text { Prevalence } \\
\text { (\%) }\end{array}$ & p-value for $\chi^{2}$-trend test \\
\hline \multicolumn{4}{|c|}{$\operatorname{Male}(n=3,971)$} & \multirow{6}{*}{$<0.001$} \\
\hline $60-64$ & 1,206 & 386 & 32.0 & \\
\hline $65-74$ & 1,537 & 354 & 23.0 & \\
\hline $75-84$ & 1,033 & 146 & 14.1 & \\
\hline$\geqq 85$ & 195 & 17 & 8.7 & \\
\hline Total & 3,971 & 903 & 22.7 & \\
\hline \multicolumn{4}{|c|}{ Female $(\mathrm{n}=2,540)$} & \multirow{6}{*}{$<0.001$} \\
\hline $60-64$ & 934 & 348 & 37.3 & \\
\hline $65-74$ & 903 & 341 & 37.8 & \\
\hline $75-84$ & 575 & 152 & 26.4 & \\
\hline$\geqq 85$ & 128 & 25 & 19.5 & \\
\hline Total & 2,540 & 866 & 34.1 & \\
\hline \multicolumn{4}{|c|}{ Total $(\mathrm{n}=6,511)$} & \multirow{6}{*}{$<0.001$} \\
\hline $60-64$ & 2,140 & 734 & 34.3 & \\
\hline $65-74$ & 2,440 & 695 & 28.5 & \\
\hline $75-84$ & 1,608 & 298 & 18.5 & \\
\hline$\geqq 85$ & 323 & 42 & 13.0 & \\
\hline Total & 6,511 & 1,769 & 27.2 & \\
\hline
\end{tabular}

Table 2. Comparisons of characteristics of NAFLD among elderly agricultural and fishing screened subjects $(\mathrm{n}=6,511)$.

\begin{tabular}{|c|c|c|c|c|}
\hline \multirow[b]{2}{*}{ Variables } & \multicolumn{2}{|c|}{ NAFLD } & \multirow[b]{2}{*}{$\begin{array}{c}\text { Total } \\
(\mathrm{n}=6,511) \\
\text { Mean } \pm \text { SD }\end{array}$} & \multirow[b]{2}{*}{$\begin{array}{l}\mathrm{p} \text {-value } \\
\text { for t-test }\end{array}$} \\
\hline & $\begin{array}{c}\text { No } \\
(\mathrm{n}=4,742) \\
\text { Mean } \pm \text { SD }\end{array}$ & $\begin{array}{c}\text { Yes } \\
(n=1,769) \\
\text { Mean } \pm \text { SD }\end{array}$ & & \\
\hline Age (year) & $70.13 \pm 9.43$ & $66.98 \pm 8.74$ & $69.28 \pm 9.35$ & $<0.001$ \\
\hline $\mathrm{SBP}(\mathrm{mmHg})$ & $135.49 \pm 41.5$ & $137.41 \pm 35.41$ & $136.01 \pm 39.94$ & $<0.001$ \\
\hline DBP $(\mathrm{mmHg})$ & $80.85 \pm 25.31$ & $82.81 \pm 22.67$ & $81.49 \pm 24.35$ & $<0.001$ \\
\hline $\mathrm{ALT}(\mathrm{U} / \mathrm{L})$ & $31.35 \pm 20.99$ & $35.98 \pm 25.87$ & $32.61 \pm 22.51$ & $<0.001$ \\
\hline BMI $\left(\mathrm{Kg} / \mathrm{m}^{2}\right)$ & $26.11 \pm 2.62$ & $27.08 \pm 2.39$ & $26.37 \pm 2.52$ & $<0.001$ \\
\hline Total cholesterol (mg/dl) & $200.97 \pm 35.46$ & $210.02 \pm 37.14$ & $203.43 \pm 36.14$ & $<0.001$ \\
\hline Triglyceride (mg/dl) & $127.14 \pm 90.39$ & $159.76 \pm 111.41$ & $136.01 \pm 97.63$ & $<0.001$ \\
\hline HDL (mg/dl) & $55.3 \pm 15.41$ & $51.86 \pm 13.93$ & $54.36 \pm 15.1$ & $<0.001$ \\
\hline Fasting plasma glucose (mg/dl) & $97.77 \pm 25.86$ & $103.76 \pm 30.52$ & $99.39 \pm 27.34$ & $<0.001$ \\
\hline
\end{tabular}

Table 3. Gender specific comparisons of characteristics of NAFLD among elderly agricultural and fishing screened subjects $(n=6,511)$.

\begin{tabular}{|c|c|c|c|c|c|c|}
\hline & & Male & & & Female & \\
\hline Variable & $\begin{array}{c}\text { With } \\
\text { NAFLD } \\
\text { Mean } \pm \text { SD }\end{array}$ & $\begin{array}{c}\text { Without } \\
\text { NAFLD } \\
\text { Mean } \pm \text { SD }\end{array}$ & p-value & $\begin{array}{c}\text { With } \\
\text { NAFLD } \\
\text { Mean } \pm \text { SD }\end{array}$ & $\begin{array}{c}\text { Without } \\
\text { NAFLD } \\
\text { Mean } \pm \text { SD }\end{array}$ & p-value \\
\hline Age(year) & $66.63 \pm 8.8$ & $70.58 \pm 9.18$ & $<0.0001$ & $67.34 \pm 8.67$ & $69.32 \pm 9.82$ & $<0.0001$ \\
\hline $\mathrm{SBP}(\mathrm{mmHg})$ & $137.71 \pm 21.14$ & $136.52 \pm 48.61$ & 0.29 & $137.09 \pm 45.79$ & $133.6 \pm 23.28$ & 0.04 \\
\hline $\mathrm{DBP}(\mathrm{mmHg})$ & $82.36 \pm 22.17$ & $81.08 \pm 23.18$ & 0.46 & $81.23 \pm 29.92$ & $78.03 \pm 22.27$ & 0.003 \\
\hline ALT(U/L) & $38.21 \pm 31.4$ & $32.54 \pm 22.73$ & $<0.0001$ & $33.66 \pm 18.13$ & $29.18 \pm 17.14$ & $<0.0001$ \\
\hline $\operatorname{BMI}\left(\mathrm{Kg} / \mathrm{m}^{2}\right)$ & $27.07 \pm 10.99$ & $26.73 \pm 70.17$ & 0.79 & $27.08 \pm 4.24$ & $24.97 \pm 7.51$ & $<0.0001$ \\
\hline Total cholesterol (mg/dl) & $204.15 \pm 35.1$ & $195.53 \pm 33.59$ & $<0.0001$ & $216.13 \pm 38.23$ & $210.95 \pm 36.61$ & 0.0009 \\
\hline Triglyceride(mg/dl) & $168.71 \pm 128.61$ & $129.72 \pm 100.07$ & $<0.0001$ & $150.43 \pm 89.16$ & $122.42 \pm 69.01$ & $<0.0001$ \\
\hline $\mathrm{HDL}(\mathrm{mg} / \mathrm{dl})$ & $48.31 \pm 12.97$ & $52.34 \pm 14.44$ & $<0.0001$ & $55.56 \pm 13.94$ & $60.71 \pm 15.67$ & $<0.0001$ \\
\hline $\begin{array}{l}\text { Fasting plasma } \\
\text { glucose }(\mathrm{mg} / \mathrm{dl})\end{array}$ & $103.48 \pm 30.46$ & $97.91 \pm 26.13$ & $<0.0001$ & $104.05 \pm 30.6$ & $97.5 \pm 25.37$ & $<0.0001$ \\
\hline
\end{tabular}

(female vs. male, $\mathrm{OR}=1.82,95 \% \mathrm{CI}: 1.61-2.08)$, age $(\mathrm{OR}=0.97,95 \% \mathrm{CI}$ : 0.96-0.99), and the presence of higher ALT (yes vs. no, $\mathrm{OR}=1.45$, 95\%CI: 1.25-1.67), higher BMI (yes vs. no, OR=2.40, 95\%CI: 2.12 2.72), hypercholesterolemia (yes vs. no, $\mathrm{OR}=1.35,95 \% \mathrm{CI}$ : 1.19-1.53), hypertriglyceridemia (yes vs. no, $\mathrm{OR}=1.44,95 \% \mathrm{CI}: 1.25-1.64$ ), lower HDL (yes vs. no, $\mathrm{OR}=1.26,95 \% \mathrm{CI}$ : 1.09-1.45), and higher fasting plasma glucose (yes vs. no, OR=1.49, 95\%CI: 1.31-1.69) appeared to be statistically significantly related to NAFLD. In addition, the data presented in Table 4 also show the dramatically different results of multiple logistic regression of the data as stratified by gender.
For females, hypertension $(\mathrm{OR}=1.18,95 \% \mathrm{CI}: 1.00-1.40)$, and lower $\mathrm{HDL}(\mathrm{OR}=1.31,95 \% \mathrm{CI}: 1.10-1.56)$ were significantly related to NAFLD but these were not so for males.

\section{Discussion}

\section{Prevalence and cardiovascular factors for the development of NAFLD}

In the Chinese population, ultrasound surveys for fatty liver (any cause) were first published in the mid-1990s from mainland 
Sun CT (2017) Clinical epidemiology of prevalence and cardiovascular risk factors of nonalcoholic fatty liver disease among the elderly agricultural and fishing population in Taiwan

Table 4. Multiple logistic regression of associated factors for NAFLD among elderly agricultural and fishing screened subjects ( $\mathrm{n}=6511)$.

\begin{tabular}{|c|c|c|c|c|c|c|}
\hline & \multicolumn{2}{|c|}{$\begin{array}{c}\text { Female } \\
(\mathrm{n}=\mathbf{2 , 5 4 0 )}\end{array}$} & \multicolumn{2}{|c|}{$\begin{array}{c}\text { Male } \\
(n=3,971)\end{array}$} & \multicolumn{2}{|c|}{$\begin{array}{c}\text { Total } \\
(\mathrm{n}=6,511)\end{array}$} \\
\hline & OR & $95 \% \mathrm{CI}$ & OR & $95 \% \mathrm{CI}$ & OR & $95 \% \mathrm{CI}$ \\
\hline Gender (female vs. male) & ---- & ---- & ---- & $-\cdots$ & 1.82 & $1.61-2.08$ \\
\hline Age (yrs) & 0.96 & $0.95-0.97$ & 0.97 & $0.96-0.98$ & 0.97 & $0.96-0.99$ \\
\hline Hypertension (yes vs. no) & 1.18 & $1.00-1.40$ & 0.88 & $0.72-1.07$ & 1.04 & $0.92-1.19$ \\
\hline Higher ALT (yes vs. no) & 1.33 & $1.11-1.60$ & 1.62 & $1.29-2.04$ & 1.45 & $1.25-1.67$ \\
\hline Higher BMI (yes vs. no) & 2.18 & $1.84-2.58$ & 2.64 & $2.20-3.17$ & 2.40 & $2.12-2.72$ \\
\hline Hypercholesterolemia (yes vs. no) & 1.47 & $1.25-1.73$ & 1.22 & $1.01-1.48$ & 1.35 & $1.19-1.53$ \\
\hline Hypertriglyceridemia (yes vs. no) & 1.32 & $1.10-1.58$ & 1.57 & $1.27-1.93$ & 1.44 & $1.25-1.64$ \\
\hline Lower HDL (yes vs. no) & 1.31 & $1.10-1.56$ & 1.21 & $0.95-1.56$ & 1.26 & $1.09-1.45$ \\
\hline Higher fasting plasma glucose(yes vs. no) & 1.39 & $1.17-1.64$ & 1.64 & $1.34-1.99$ & 1.49 & $1.31-1.69$ \\
\hline
\end{tabular}

China [11]. Although NAFLD has been demonstrated to be present in several occupational populations and has been shown to be responsible for more than one third of patients with asymptomatic disorder, little is known about the baseline clinical and biochemical profiles of elderly sub-population $[4,9,12]$. The prevalence of a NAFLD amongst different screened populations appears to vary according to the results of different studies conducted in different countries [1315]. This disparity would likely be largely due to differences between different population stocks in addition to differences in the specifics of diagnostic criteria for such a NAFLD. This is one of the possible reasons that the prevalence of NAFLD in this elderly agricultural and fishing population (27.2\%) was lower than the corresponding figure presented in a previous occupational population-based study conducted in Chinese populations $[4,9,12]$. Our study demonstrated NAFLD to be a disease of elderly age group with a mean age at presentation being 67 years. Previous study revealed the higher morbidity of NAFLD in aged 40-60 years [16]. This also might partially explain the apparently low prevalence of NAFLD observed in our study. In addition, healthy work effect could affect the correct estimation of NAFLD based on voluntarily admitted a physical check-up (self-selection bias).

In the adult population, males are about three times more likely to develop hepatocellular carcinoma (HCC) as a complication of chronic liver disease, including NAFLD [17]. Oestrogen inhibits the secretion of IL- 6 from Kupffer cells exposed to necrotic hepatocytes and reduces circulating concentrations of IL- 6 in male mice treated with the diethylnitrosamine $[17,18]$. The gender disparity in liver cancer and inflammation may thus be because of oestrogen-dependent differences in IL-6 production [17]. Previous study also has demonstrated that NAFLD has a more even distribution between male and female and the possible reason was female hormones protect against NAFLD has been postulated and supported by evidence that NAFLD is twice as common in postmenopausal women as in premenopausal women $[19,20]$. However, it was interesting that that elderly female gender represented significant risk factors related to the likelihood of a NAFLD. Such a finding would appear to be inconsistent with the results of other studies for general population or occupational population conducted elsewhere $[3,4,7-9,11,12]$. The proportion of obesity in males was higher than females among aged $<50$ yrs but the prevalence of an obesity for males proved to be substantially greater than it was for females among 60 years or above [21]. In the Asian countries, the age peak of diagnosed NAFLD in males and females were $40-49$ yrs and $₫ 50$ yrs, respectively [22]. Maybe this is why that females showed a greater prevalence of NAFLD than did males in the elderly population.

NAFLD is considered a hepatic manifestation of the metabolic syndrome, a condition which has greatly increased in past decades [23]. Subjects with the metabolic syndrome are at an increased risk of developing diabetes mellitus and cardiovascular disease, as well as increased mortality from cardiovascular disease and all causes, including fatty liver disease [24]. More than 80 years have passed since the introduction of the concept of the clustering of metabolic and physiological abnormalities in 1923, however, there are still many cloud-clusters over metabolic syndrome that need to be further unraveled [24]. In this study, hypertension, hypercholesterolemia, hypertriglyceridemia, lower HDL, and higher fasting plasma glucose, the components of metabolic syndrome, are significantly related to NAFLD. Metabolic syndrome could be viewed as a strong predictor of NAFLD and NAFLD is also a good predictor for the clustering of components of risk factors for metabolic syndrome [25,26]. In addition, clinical manifestation of NAFLD is usually absent or subtle with abnormal aminotransferase or incidental radiographic findings of fatty liver [27]. The pathogenesis of NAFLD is thought to be due to multi-hit process involving insulin resistance, oxidative stress, apoptotic pathways and adipocytokines $[27,28]$.

The history of chronic liver disease is usually long and asymptomatic before the development of late-stage disease. The only markers of liver damage during this long phase may be increased serum levels of enzymes such as ALT, AST, and gamma-glutamyltransferase (GGT) [9]. Consistent with the results of other studies [4,9,29], our results revealed that a higher ALT were highly associated with NAFLD.

The determination of the serum ALT level constitutes the mostfrequently applied test for the identification of patients suffering from liver disease. This parameter also acts as a surrogate marker for disease severity and/or an index of hepatic activity [30]. Previous studies showed that the number of metabolic syndrome components has increased, the prevalence and odds ratio for having increased ALT activity were also significantly increased [31]. The possible mechanism for such a finding may relate to the observation that serum ALT concentrations were related to hepatic insulin resistance and suggested that a raised ALT reflects fatty changes in the liver [1]. In the mainland China and Taiwan, NAFLD now is viewed as one of major causes of asymptomatic elevation of liver enzymes among those participating in regular health examinations [4].

\section{Perceived limitations}

One of major limitations of this study was diagnosis of NAFLD for elderly participants only by ultrasonography although liver biopsy remains the gold standard. The later is however invasive with many unpredicted risks and ethically not acceptable for this kind of study [27]. Previous reports revealed that from clinical viewpoint, ultrasonography was widely used for the detection of NAFLD with high sensitivity (up to $89 \%$ ) and specificity (up to $93 \%$ ) [32]. We suggested this technique to be suitable for the diagnosis of NAFLD in the population-based mass 
Sun CT (2017) Clinical epidemiology of prevalence and cardiovascular risk factors of nonalcoholic fatty liver disease among the elderly agricultural and fishing population in Taiwan

screening. However, different studies may elect to set slightly different definitions, such that our estimation of what constituted NAFLD could have suffered from some level of misclassification-bias. Secondly, the potential impact on the prevalence and the study-observed NAFLDrelated risk factors were due to the screening of elderly population from one area, in our estimation, inevitable. The study still retained sufficient statistical power to evaluate the presence of any gender differences among the various risk factors for NAFLD given the rather large sample size. Finally, our measurements were conducted at only a single point in time and, therefore, may not reflect long-term exposure to important demographic or biochemical factors [4]. The improvement to such a quandary would be to conduct a number of prospective longitudinal analogous studies to see if they would complement the cross-sectional findings of this study.

\section{Conclusion}

Several gender-related differences were noted pertaining to the prevalence of and relationship between hypertension, lower HDL, and NAFLD in this occupational elderly study population. Further studies not only are needed to elucidate the temporal sequence of events that typically lead to NAFLD, but also studies should develop more-satisfactory and non-invasive indicators of liver pathology and then assess how gender-related differences are related NAFLD among elderly population.

\section{Competing Interests}

The authors declare that they have no competing interests.

\section{Authors' Contributions}

Yi-Chun Hu, Yu-Fen Chen, Hsi-Che Shen, and Tao-Hsin Tung carried out the study and drafted the manuscript. Chi-Te Sun, MingChih Chen, Yu-Fen Chen and Tao-Hsin Tung participated in the design of the study and performed the statistical analysis. Chi-Te Sun, Ming-Chih Chen, Hsi-Che Shen and Tao-Hsin Tung conceived of the study, and participated in its design and coordination. All authors read and approved the final manuscript.

\section{Conflicts of Interest}

We certify that all affiliations with or financial involvement in, within the past 5 years and foreseeable future, any organization or entity with a financial interest in or financial conflict with the subject matter or materials discussed in the manuscript are completely disclosed (e.g., employment, consultancies, honoraria, stock ownership or options, expert testimony, grants or patents received or pending, royalties).

\section{Acknowledgements}

This study was supported by the grants from the National Science Council (NSC-95-2314-B-002-MY3) and (NSC-98-2314-B-350-002MY3). The authors have no proprietary interest in any aspect of this study. There was no additional financial support from public or private sources.

\section{References}

1. Chen ZW, Chen LY, Dai HL, Chen JH, Fang LZ (2008) Relationship between alanine aminotransferase levels and metabolic syndrome in nonalcoholic fatty liver disease. $J$ Zhejiang Univ Sci B 9: 616-22.

2. Saadeh S (2007) Nonalcoholic Fatty liver disease and obesity. Nutr Clin Pract 22: 1-10. [Crossref]

3. Ong JP, Younossi ZM (2007) Epidemiology and natural history of NAFLD and NASH Clin Liver Dis 11: 1-16, vii. [Crossref]
4. Tung TH, Chiu WH, Lin TH, Shih HC, Hsu CT (2011) An exploration of prevalence and associated factors of nonalcoholic fatty liver disease in the Taiwanese police service. Iranian J Publ Health 40: 54-62.

5. Brunt EM (2004) Nonalcoholic steatohepatitis. Semin Liver Dis 24: 3-20. [Crossref]

6. Liu CM, Tung TH, Liu JH, Chen VT, Lin CH, et al. (2005) commumity-based epidemiological syudy of elevated serum alanine aminotransferase levels in Kinmen, Taiwan. World J Gastroenterol 11: 1616-1622.

7. Dai HF, Shen Z, Yu CH, Zhang XC, Li YM (2008) Epidemiology of fatty liver in an islander population of China: a population-based case-control study. Hepatobiliary Pancreat Dis Int 7: 373-378.

8. Lin YC1, Chou SC, Huang PT, Chiou HY (2011) Risk factors and predictors of nonalcoholic fatty liver disease in Taiwan. Ann Hepatol 10: 125-132. [Crossref]

9. Tung TH, Chang TH, Chiu WH, Lin TH, Shih HC, et al. (2011) Clinical correlation of nonalcoholic fatty liver disease in a Chinese taxi drivers population in Taiwan: Experience at a teaching hospital. BMC Res Notes 4: 315 .

10. Shen HC, Zhao ZH, Hu YC, Chen YF, Tung TH (2014) Relationship between obesity, metabolic syndrome, and nonalcoholic fatty liver disease in the elderly agricultural and fishing population of Taiwan. Clin Interv Aging 9: 501-508.

11. Fan JG (2001) Steatohepatitis studies in China. Shijie Huaren Xiaohua Zazhi 9: 6-10.

12. Fan JG, Li F, Cai XB, Peng YD, Ao QH, et al. (2007) The importance of metabolic factors for the increasing prevalence of fatty liver in Shanghai factory workers. $J$ Gastroenterol Hepatol 22: 663-8.

13. Chen CH, Huang MH, Yang JC, Nien CK, Yang CC, et al (2006) Prevalence and risk factors of nonalcoholic fatty liver disease in an adult population of Taiwan: metabolic significance of nonalcoholic fatty liver disease in nonobese adults. J Clin Gastroenterol 40: 745-752.

14. Caballería L, Auladell MA, Torán P, Pera G, Miranda D, et al. (2008) Risk factors associated with non-alcoholic fatty liver disease in subjects from primary care units. A case-control study. BMC Gastroenterology 8: 44

15. Bedogni G, Miglioli L, Masutti F, Tiribelli C, Marchesini G, et al. (2005) Prevalence of and risk factors for nonalcoholic fatty liver disease: the Dionysos nutrition and liver study. Hepatology 42: 44-52. [Crossref]

16. Bayard M, Holt J, Boroughs E (2006) Nonalcoholic fatty liver disease. Am Fam Physician 73: 1961-1968. [Crossref]

17. Barshop NJ, Sirlin CB, Schwimmer JB, Lavine JE (2008) Review article: epidemiology, pathogenesis and potential treatments of paediatric non-alcoholic fatty liver disease Aliment Pharmacol Ther 28: 13-24.

18. Naugler WE, Sakurai T, Kim S, Maeda S, Kim K, et al. (2007) Gender disparity in liver cancer due to sex differences in MyD88-dependent IL-6 production. Science 317: 121-124. [Crossref]

19. Carulli L, Lonardo A, Lombardini S, Marchesini G, Loria P (2006) Gender, fatty liver and GGT. Hepatology 44: 278-279. [Crossref]

20. Lazo M, Clark JM (2008) The epidemiology of nonalcoholic fatty liver disease: a global perspective. Semin Liver Dis 28: 339-350. [Crossref]

21. Hwang LC1, Bai CH, Chen CJ (2006) Prevalence of obesity and metabolic syndrome in Taiwan. J Formos Med Assoc 105: 626-635. [Crossref]

22. Chitturi S, Farrell GC, Hashimoto E, Saibara T, Lau GK, et al. (2007) Asia-Pacific Working Party on NAFLD. Non-alcoholic fatty liver disease in the Asia-Pacific region definitions and overview of proposed guidelines. J Gastroenterol Hepatol 22: 778-787.

23. Lin YC, Chou SC, Huang PT, Chiou HY (2011) Risk factors and predictors of nonalcoholic fatty liver disease in Taiwan. Ann Hepatol 10: 125-132. [Crossref]

24. Fan JG, Zhu J, Li XJ, Chen L, Lu YS, et al. (2005) Fatty liver and the metabolic syndrome among Shanghai adults. J Gastroenterol Hepatol 20: 1825-1832. [Crossref]

25. Fan JG, Peng YD (2007) Metabolic syndrome and non-alcoholic fatty liver disease Asian definitions and Asian studies. Hepatobiliary Pancreat Dis Int 6: 572-578.

26. Huang HL, Lin WY, Lee LT, Wang HH, Lee WJ, et al. (2007) Metabolic syndrome is related to nonalcoholic steatohepatitis in severely obese subjects. Obes Surg 17: 14571463. [Crossref]

27. Onyekwere CA, Ogbera AO, Balogun BO (2011) Non-alcoholic fatty liver disease and the metabolic syndrome in an urban hospital serving an African community. Ann Hepatol 10: 119-124. 
Sun CT (2017) Clinical epidemiology of prevalence and cardiovascular risk factors of nonalcoholic fatty liver disease among the elderly agricultural and fishing population in Taiwan

28. Hui JM, Hodge A, Farrell GC, Kench JG, Kriketos A, et al. (2004) Beyond insulin resistance in NASH: TNF-alpha or adiponectin? Hepatology 40: 46-54. [Crossref]

29. Fan JG, Farrell GC (2009) Epidemiology of non-alcoholic fatty liver disease in China. J Hepatol 50: 204-210. [Crossref]

30. Pratt DS, Kaplan MM (2000) Evaluation of abnormal liver-enzyme results in asymptomatic patients. $N$ Engl J Med 342: 1266-1271.
31. Kakizaki S, Takizawa D, Yamazaki Y, Nakajima Y, Ichikawa T, et al. (2008) Nonalcoholic fatty liver disease in Japanese patients with severe obesity who received laparoscopic Roux-en- Y gastric bypass surgery (LRYGB) in comparison to nonJapanese patients. J Gastroenterol 43: 86-92.

32. Li H, Wang YJ, Tan K, Zeng L, Liu L, et al. (2009) Prevalence and risk factors of fatty liver disease in Chengdu, Southwest China. Hepatobiliary Pancreat Dis Int 8 : 377-382. [Crossref]

Copyright: C2017 Sun CT. This is an open-access article distributed under the terms of the Creative Commons Attribution License, which permits unrestricted use, distribution, and reproduction in any medium, provided the original author and source are credited. 